\title{
TREND OF USE OF DIFFERENT ANTIMIGRAINE MEDICATIONS AND AWARENESS OF MIGRAINE, SURVEY BASED STUDY IN JALANDHAR
}

\author{
AMANDEEP KAUR ${ }^{1}$, HARMANPREET SINGH ${ }^{2,3 *}$, SUKSHAM GUPTA ${ }^{1}$, JASJEET KAUR NARANG ${ }^{4}$, YASH PAUL SINGLA ${ }^{5}$, \\ AVNEET KAUR ${ }^{6}$ \\ ${ }^{1}$ Department of School of Pharmaceutical Sciences, Lovely Professional University, Phagwara - 144411, Punjab, India. ${ }^{2}$ Department of ? \\ I. K. G Punjab Technical University, Kapurthala, Punjab, India. ${ }^{3}$ Department of Pharmaceutics, Lovely Institute of Technology \\ (Pharmacy), Lovely Professional University, Phagwara - 144411, Punjab, India. ${ }^{4}$ Department of , Khalsa College of Pharmacy, Amritsar - \\ 143001, Punjab, India. ${ }^{5}$ Controller of Examinations, Guru Jambheshwar University of Science and Technology, Hisar, Haryana, India. \\ ${ }^{6}$ Department of Universiti Tunku Abdul Rahman, Kuala Lumpur, Malaysia. Email: harmanpreetmadaan@gmail.com
}

Received: 14 July 2017, Revised and Accepted: 25 July 2017

ABSTRACT

Objective: A brain disease, migraine is a special type of headache that causes highly intense, throbbing quality pain in half head or any one side of the head. It may be due to several reasons such as food intake, sleep disturbance, and stress or tension. Hormonal disturbance can result in migraine. There is no specific treatment for migraine. Analgesics or pain killers may prove effective in migraine. To prevent it cautions must be taken. Our study aims to find out the awareness and prevalence of migraine among students of different schools, colleges, universities, and professional institutes of Jalandhar city. Further, the drug consumption pattern of most prominent used antimigraine medications was also calculated.

Method: The cross-sectional data were collected through a questionnaire from the random sample in the month from August 2016 to November 2016 in Jalandhar. To check the drug consumption, daily defined dose (DDDs) or drug usage has been calculated using the DDD recommended by the World Health Organization.

Results: According to our survey, $80 \%$ candidates have heard about the term "migraine." $36 \%$ candidates are aware about the causes, $58 \%$ aware about the signs and symptoms of migraine while $23 \%$ candidates are aware about the treatment. The overall awareness rate of migraine in candidates is about $45 \%$.

Conclusion: The prevalence of migraine is more in women than men by a factor of about 3:1. Triptans are mostly found to be effective for the treatment of migraine. The main cause of migraine was found to be stress or tension and the common symptom of migraine was throbbing or pulsating pain on one side of the head.

Keywords: Migraine, Daily defined dose, Triptans.

(C) 2017 The Authors. Published by Innovare Academic Sciences Pvt Ltd. Thisis an open access article under the CC BYlicense (http://creativecommons. org/licenses/by/4. 0/) DOI: http://dx.doi.org/10.22159/ajpcr.2017.v10s4.21333

\section{INTRODUCTION}

Migraine is a periodic headache, unilateral or bilateral, causing pulsating or throbbing pain which gets worsted by physical activities and/or emotional stress [1]. It causes one sided intense pain of head [2]. Migraine is the $5^{\text {th }}$ most important cause for women among all diseases worldwide causing disability, and for men, it is one of the top 20 diseases [3]. According to the Global Burden of Disease Survey 2000 (GBD 2000), conducted by the World Health Organization (WHO), migraine was the $19^{\text {th }}$ most disabling illness in the world, but according to its updating in 2013 (GBD 2013), it is the $6^{\text {th }}$ highest disease worldwide causing disability [4,5]. After tension headache, the second general kind of primary headaches are the migraine headaches. A headache which is not caused by another disease or condition is called a primary headache [6]. It is considered as persistent unilateral headache united with neurologic and gastrointestinal disturbances that can severely influence the quality of living and daily activities [7]. According to Best Places President Bert Sperling, migraine is most commonly found than asthma and diabetes, however, there are still many people who have migraine symptoms, but they don't get medical help [8]. Migraine also raises the possibility for further physical and psychiatric circumstances [9]. Hence, we conduct a survey to check the awareness and prevalence of migraine in population of Jalandhar. Our aims were also to enhance the awareness about migraine and to check the most prominent used antimigraine medications. The cross-sectional and random method was used to collect data from the sample through a specially planned questionnaire.

\section{Phases of a migraine}

Migraine usually starts in childhood, adolescence or early adulthood. Migraine may involve following four phases $[2,10,11]$.

\section{Prodrome (early warning)}

It takes place hours to days before migraine without headache. It involves some changes such as neck rigidity, constipation/diarrhea, and mood fluctuations.

\section{Aura (pre-migraine)}

It is neurological phenomena which involve visual disturbances just before the headache. Aura may arise before or throughout migraines. In general, people experience migraines without aura. Occasionally auras can also include sensory, motor, or verbal disturbances. These symptoms strengthen over several minutes and last for 20-60 minutes.

Pain phase (during headache/headache phase)

If migraine is untreated, it generally lasts from 4 to $72 \mathrm{hrs}$. The frequency of headache occurs, changes from individual to individual. During a migraine, you may be subjected to nausea and vomiting. 


\section{Postdrome (after headache)}

It is the final phase which occurs at the end of a migraine attack. For around 24 hrs, you may suffer from confusion, irritability, faintness, and sensitivity to light and sound.

\section{Pathophysiology}

The exact mechanism of the migraine attack is unknown. An aura of sensory or visual change instantly introduces about $30 \%$ of migraine attacks. These migraines are known as migraine with aura (classical migraine). All other migraines are known as migraine without aura (common migraine). According to vascular theory, vasodilatation and the concurrent involuntary stimulation of sensory nerve endings cause migraine [7]. According to the recent theory, vasoactive neuropeptides released by trigeminal nerve terminals travel to the outer covering of the brain (meninges) causes inflammation and dilation of meningeal blood vessels. Serotonin (5-HT) and magnesium level decreases during migraine which causes vasodilatation and tend to cause migraine attack [12]. According to this concept, calcitonin gene related peptide (CGRP) is a neurotransmitter, which leads to the release of proinflammatory cytokines from the meningeal mast cells cause vasodilatation and leads to migraines headache [1].

\section{Causes}

The exact origin of migraine is unclear. Migraine is a brain disease and triggers of migraine attacks may include $[11,13]$ :

- Stress or tension.

- Bright lights.

- Disturbance in the sleep/meals.

- Strong odors like perfume.

- Specific medications.

- Hormonal changes in women (estrogens and progesterone).

- Foods and beverages such as aged cheese, salty foods, processed foods, caffeine, chocolate, red wine, and alcohol

- Food additives or preservatives such as nitrates, and monosodium glutamate.

- Fruits such as avocado, banana and citrus fruit.

\section{Signs and symptoms}

The sign and symptoms of migraine are as follows $[7,11]$ :

- Nausea, vomiting or diarrhea.

- Sensitivity to light (photophobia), sound (phonophobia) or smell.

- Disturbances in vision, smell, taste, or touch.

- Confusion, mood changes or coordination problem.

\section{Treatment}

The nondrug therapies should be used primarily. For example, a peaceful environment and adequate sleep, in acute migraine attack but in repeated attacks, two types of therapies may be used: Prophylactic therapy and abortive therapy. Prophylactic therapy is used to avoid or diminish recurrence. Abortive therapy is used to treat acute migraine headaches [7].

The non-pharmacological therapies for migraine include: Acupuncture, massage, relaxation techniques, exercise, spinal manipulation, talk therapy, transcranial magnetic stimulation, diet changes, herbal remedies, and sleep [14]. For treatment of severe attack of migraine, triptans are used, e.g., sumatriptan and zolmitriptan are used in migraine with or without aura whereas frovatriptan is used for menstrual migraine $[15,16]$.

The drugs used for the treatment of acute migraine attacks are simple analgesics (e.g., aspirin, paracetamol; with or without metoclopramide); ergotamine; NSAIDs (naproxen, ibuprofen). The drugs used in the prophylactic therapies for migraine include: $5-\mathrm{HT}_{2}$ receptor antagonist (pizotifen); beta-adrenergic antagonists (propranolol, atenolol, and metoprolol); tricyclic antidepressants (amitriptyline); calcium channel blockers (verapamil); anticonvulsants (valproic acid, gabapentin); alpha-adrenoceptor agonist (clonidine) [1,17].

\section{Prevention}

Migraine can also be prevented by following precautions [18]:

- Don't miss meals and avoid foods described in causes.

- Take sufficient but not unnecessary sleep.

- Keep a headache diary to know about your migraine triggers.

According to the WHO, "The daily defined dose (DDD) is the assumed average maintenance dose per day for a drug used for its main indication in adults". It is used to measure the drug consumption. DDD is a measurement unit. It is not the prescribed or recommended daily dose by the physician. The prescribed doses for individual patients can be higher or lower than WHO measured DDD, depending on individual variables such as age/weight [19].

\section{METHODS}

A survey based study was conducted to check the awareness and prevalence of migraine in Jalandhar city. A cross-sectional and random method was used to collect data from various schools, colleges, universities, hospitals in Jalandhar city. Data from 300 candidates $(n=300)$ were collected through a specially planned questionnaire (Table 1) and were analyzed statistically using various figures and tables.

To check the most prominent used antimigraine medications, data were collected from various pharmacies and hospitals. We also collected data from migraine patients about the various combinations of drugs available under the brand name used by them for the treatment of migraine and what are their dosage frequencies per week. To check the antimigraine drug consumption, drug usage (DDDs) has been calculated using the following formula [20].

Drug usage (DDDs)=Items issued $\times$ Amount of drug per item/WHO recommended DDD.

\section{RESULTS AND DISCUSSION}

A survey was conducted about migraine. 9 questions were included in our survey (Table 1), which were asked from 300 candidates to check the awareness and prevalence of migraine. Some additional questions were also asked from the migraine sufferers to know about the causes and symptoms of their migraine and also about the effective therapies, foods and medications used by them for treating their migraine.

According to the analysis of first question asked as per Table 1, there were $80 \%$ candidates who have heard about the disease called migraine, whereas there were $20 \%$ candidates too who even have not heard about the term "migraine."

The second question was asked to find out general knowledge of migraine as per Table 1, 70\% candidates were having knowledge about

Table 1: Questionnaire for assessment of awareness and prevalence of migraine

\begin{tabular}{|c|c|c|c|}
\hline S.No. & Questions and options & Yes & No \\
\hline 1 & $\begin{array}{l}\text { Have you ever heard about the disease called } \\
\text { migraine? }\end{array}$ & 240 & 60 \\
\hline 2 & Do you know about migraine? & 210 & 90 \\
\hline 3 & $\begin{array}{l}\text { Do you know the difference between headache } \\
\text { and migraine? }\end{array}$ & 168 & 132 \\
\hline 4 & $\begin{array}{l}\text { Does any member of your family suffer from } \\
\text { migraine? }\end{array}$ & 54 & 246 \\
\hline 5 & Do you know about the cause of migraine? & 108 & 192 \\
\hline 6 & $\begin{array}{l}\text { Do you know about the signs and symptoms } \\
\text { of migraine? }\end{array}$ & 174 & 126 \\
\hline 7 & Do you know about the treatment of migraine? & 69 & 231 \\
\hline 8 & $\begin{array}{l}\text { Do you know about the preventive measures } \\
\text { of migraine? }\end{array}$ & 57 & 243 \\
\hline 9 & Are you suffering from migraine? & 42 & 258 \\
\hline
\end{tabular}


the migraine while $30 \%$ candidates were having no idea about the migraine.

The third question was asked to find whether they know about the difference of normal headache and migraine. There were $56 \%$ candidates who knew the difference between headache and migraine; and $44 \%$ candidates too who did not know the difference between headache and migraine.

The fourth question was asked to find out the family history of migraine. $18 \%$ candidates were those who are having family history of migraine and $82 \%$ candidates were not having family history of migraine. Out of those $18 \%$ of candidates who were having family history of migraine, there were only $31 \%$ of candidates who are suffering from migraine and $69 \%$ of candidates were also those who are not suffering from migraine till today but they are having at least one member of the family suffering from migraine. From it we conclude that, it is not mandatory that if your parents have migraine, you will also suffer from migraine but then chances of developing migraine in children increases; and it is also not like that if you do not have family history of migraine, you cannot develop migraine but if you have a family history of migraine, there are more chances that you can also suffer from migraine.

The fifth question was asked to find out awareness of causes of migraine among the population. $36 \%$ candidates were those who knew about the causes of migraine and $64 \%$ candidates were those who did not aware about the causes of migraine.

The sixth question asked among population was about the awareness of the signs and symptoms of migraine there were $58 \%$ candidates who were familiar with the signs and symptoms of migraine, whereas $42 \%$ candidates were those also who did not know about the signs and symptoms of migraine. From the familiar candidates, one question was against asked that what is the most common symptom of migraine they experience? From the result, more than $70 \%$ of candidates experience throbbing or pulsating pain in the head as the major symptom during migraine attack.

The seventh question was about the awareness of the treatment of migraine, asked from population. $23 \%$ candidates were those who were aware about the treatment of migraine, whereas $77 \%$ candidates were those who did not know about the treatment of migraine.

The eighth question asked from the population was about awareness of preventive measures of migraine. From the result, it was found that only $19 \%$ candidates were completely aware about the preventive measures of migraine whereas $81 \%$ candidates were those who were not having any awareness about the preventive measures of migraine. There were even $68 \%$ migraine sufferers also who were having no knowledge about the same. Only $32 \%$ of migraine sufferers were aware about it.

The final question asked from the population was regarding the prevalence of migraine. From the result, it was found that there were $14 \%$ candidates who are suffering from migraine while $86 \%$ candidates are not suffering from migraine. The prevalence of migraine in males was found to be $4 \%$ whereas in females, it was found to be $10 \%$. Thus, there is more prevalence of migraine in women than in men by ratio of $3: 1$. According to our survey, the prevalence of migraine in males and females depending on the age and sex has been shown in Fig. 1.

Then, one more question was also asked from the migraine sufferers, according to them what are the reason of their migraine. According to the analysis of their responses, it was found that the major cause or trigger of their migraine was stress or tension. The percentage of various causes which leads to migraine have been shown in Fig. 2.

Then, the next part of our study, i.e., various medications used by the migraine sufferers for the treatment of their migraine were also asked from them. The various medications used by them are headset, advil, saridon, diclofenac, atenolol, vasograin, aginal-AT, levera, Sibelium, migranil, etc.

The migraine sufferers, who were using therapies for the treatment of their migraine, the data about those therapies, were also collected. According to the analysis of data obtained from migraine patients, physiotherapy is found to be the most used treatment for their migraine, but there were very less number of migraine sufferers $(\sim 20 \%)$ who are using therapies for treating their migraine. The percentage of various therapies used by them has been shown in Fig. 3 but according to some candidates, apart from these therapies, massage has also found to be effective in their treatment

One question was also asked from the candidates, if they know about any food which helps in the treatment of migraine. According to their

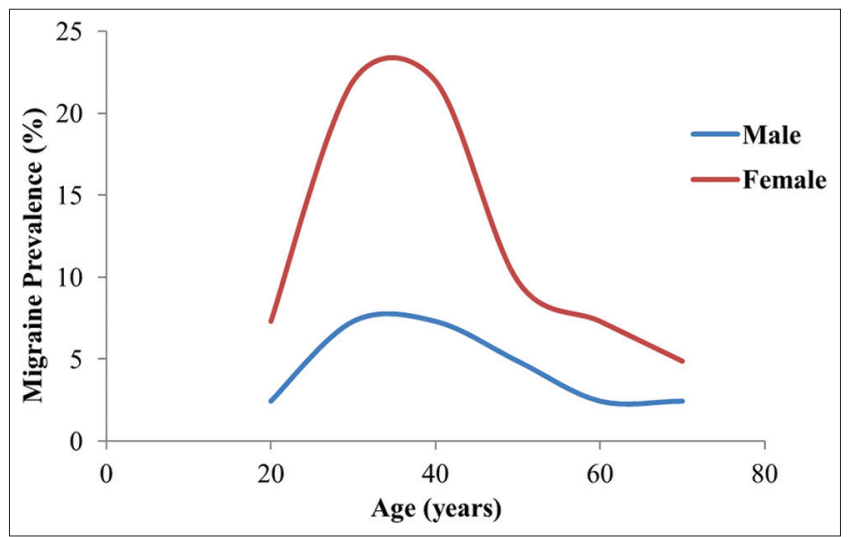

Fig. 1: Percentage of prevalence of migraine according to age and $\operatorname{sex}$

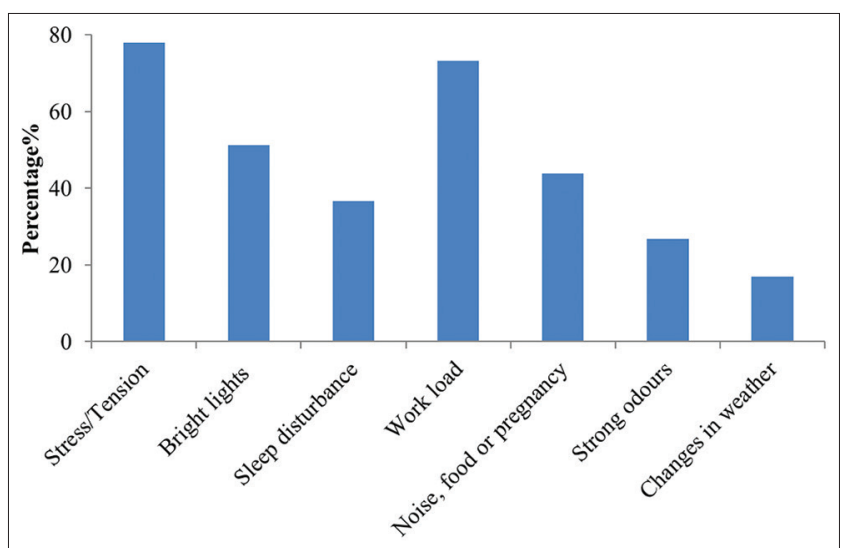

Fig. 2: Percentage of various causes of migraine from the migraine sufferers

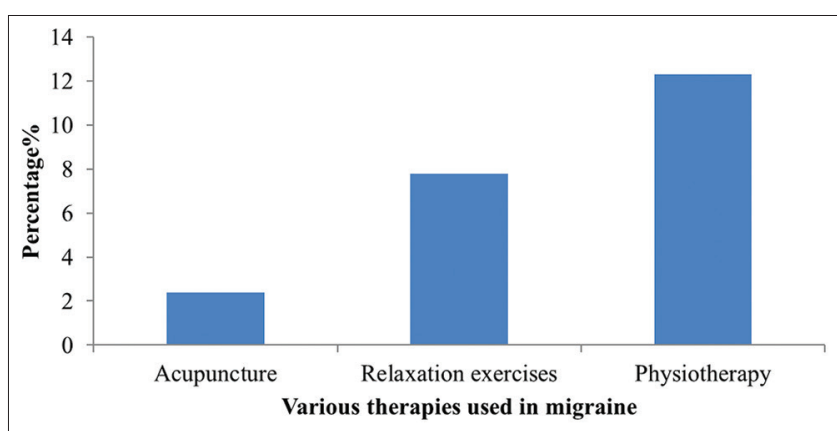

Fig. 3: Percentage of various therapies used for migraine 
Table 2: Calculated drug usage (DDDs) of various antimigraine medications

\begin{tabular}{|c|c|c|c|c|c|}
\hline S.No. & Generic name/Classes & WHO recommended DDD & Amount of drug per item & Items issued (tablets) & Drug usage (DDDs) \\
\hline 1 & Painkillers & & & & \\
\hline $1 \mathrm{a}$ & Acetaminophen & $3 \mathrm{~g}$ & $500 \mathrm{mg}$ & 24 & 4 \\
\hline $1 \mathrm{~b}$ & Aspirin & $3 \mathrm{~g}$ & $500 \mathrm{mg}$ & 20 & 3 \\
\hline 2 & Triptans & & & & \\
\hline $2 a$ & Sumatriptan & $50 \mathrm{mg}$ & $50 \mathrm{mg}$ & 12 & 12 \\
\hline $2 \mathrm{~b}$ & Rizatriptan & $10 \mathrm{mg}$ & $10 \mathrm{mg}$ & 10 & 10 \\
\hline 3 & Beta-blockers & & & & \\
\hline $3 b$ & Propranolol & $160 \mathrm{mg}$ & $160 \mathrm{mg}$ & 5 & 5 \\
\hline 4 & Other drugs & & & & \\
\hline $4 a$ & Ergotamine & $4 \mathrm{mg}$ & $2 \mathrm{mg}$ & 14 & 7 \\
\hline $4 \mathrm{~b}$ & Metoclopramide & $30 \mathrm{mg}$ & $10 \mathrm{mg}$ & 14 & 5 \\
\hline
\end{tabular}

DDD: Daily defined dose

responses, the foods which help in the treatment of migraine are apple, bitter gourd, sweet potatoes, ginger, grapes, cabbage, cucumber, carrot juice, and other leafy vegetables.

To check the most prominent used antimigraine medications, data were collected from migraine patients. The data were collected according to the medications used by the patients per week, and then average number of items (medications) used by the patients was calculated. Then, the drug usage (DDDs) of antimigraine medications of various classes has been estimated using the above-discussed formula of drug usage in methodology. It gives data of only approximate consumption, not an exact consumption. The calculated drug usage has been shown in Table 2. The WHO recommended DDD has been taken from WHO Collaborating Centre for Drug Statistics Methodology 2016 [21].

The drug usage of triptans was found to be more than the other categories of antimigraine medications and Sumatriptan is the most commonly used medication by the patients for treatment of their migraine.

According to data collected from migraine patients, most commonly used drugs for migraine according to brand name were found to be Suminat (Sumatriptan [50 mg]) and Migrtan (Sumatriptan [50 mg]). Other prominent medications used for the treatment of migraine by migraine patients were found to be Rizact (5 mg), Rizatan (5 mg), Vasograin (Ergotamine tartrate [1 mg]), Caffeine (100 mg), Paracetamol $(250 \mathrm{mg})$ and Prochlorperazine maleate $(2.5 \mathrm{mg})$, and Migranil (ergotamine tartrate [ $1 \mathrm{mg}$ ], anhydrous caffeine [100 mg], belladonna dry extract [10 $\mathrm{mg}]$, and paracetamol [250 $\mathrm{mg}]$ ).

\section{CONCLUSION}

After our survey, we are reached to the result that the overall awareness of migraine among students of Jalandhar city is $45 \%$. $80 \%$ candidates have heard about the term migraine. But out of that $80 \%$, only $70 \%$ knew about the migraine. We also concluded that $14 \%$ of candidates are suffering from migraine and major cause of it is stress and tension. The prevalence of migraine was found to be more in women than men by a factor of about 3:1. Finally, from the drug usage of migraine patient, it was found that sumatriptan was mostly used medication than any other drug for the treatment of the migraine.

\section{REFERENCES}

1. Satoskar RS, Bhandarkar SD, Rege NN. Pharmacotherapy of migraine. In: Satoskar RS, editor. Pharmacology and Pharmacotherapeutics. $21^{\text {st }}$ ed. India: Popular Prakashan; 2009. p. 332-4.

2. Naveed S, Hameed A, Sharif N. Awareness and prevalence of migraine, survey based study in Karachi. Int J Biol Sci Appl 2014;1(4):157-61.

3. Cady RK, Farmer K. Acute and preventative treatment of episodic migraine. In: Diamond S, Cady RK, Diamond ML, Martin VT, editors. Headache and Migraine Biology and Management. $1^{\text {st }}$ ed. USA: Academic Press; 2015. p. 69.

4. Steiner TJ, Stovner LJ, Birbeck GL. Migraine: The seventh disabler. J Headache Pain 2013;14(1):1.

5. World Health Organization. Headache Disorders;2016 Available from: http://www.who.int/mediacentre/factsheets/fs277/en. [Last cited on 2017 Jun 12].

6. University of Maryland Medical Center. Migraine Headaches;2016 Available from: http://www.umm.edu/health/medical/reports/articles/ migraine-headaches. [Last cited on 2017 Jun 12].

7. Hurney C, Faulkner D. Migraine headaches. In: Ballington DA, Laughlin MM, editors. Pharmacology for Technicians. India: New Age International Publishers; 2005. p. 133-4.

8. Migraine Again. The Best Migraine Cities in the US (and the Worst);2016 Available from: http://www.migraineagain.com/the-bestmigraine-cities-in-the-us-and-the-worst. [Last cited on 2017 Jun 12].

9. Migraine Research Foundation. Migraine Facts;2016 Available from: https://www.migraineresearchfoundation.org/about-migraine/ migraine-facts. [Last cited on 2017 Jun 12].

10. Girotra P, Singh SK, Saini D. Disentangling the intricacies of migraine: A review. CNS Neurol Disord Drug Targets 2014;13(5):776-91.

11. Mayo Clinic. Symptoms and Causes;2016 Available from: http://www. mayoclinic.org/diseases-conditions/migraine-headache/symptomscauses/dxc-20202434. [Last cited on 2017 Jun 12].

12. Buse DC, Manack AN, Fanning KM, Serrano D, Reed ML, Turkel CC, et al. Chronic migraine prevalence, disability, and sociodemographic factors: Results from the American Migraine Prevalence and Prevention Study. Headache 2012;52(10):1456-70.

13. Medline Plus. Migraine;2016 Available from: https://www.medlineplus. gov/ency/article/000709.htm. [Last cited on 2017 Jun 12].

14. Goadsby PJ. Migraine: Diagnosis and management. Intern Med J 2003;33(9-10):436-42.

15. Horne T, Smillie L. Migraine. In: Bennett PN, Brown MJ, editors. Clinical Pharmacology. $9^{\text {th }}$ ed. Spain: Churchill Livingstone; 2003. p. 326-8.

16. Kelman L. Review of frovatriptan in the treatment of migraine. Neuropsychiatr Dis Treat 2008;4(1):49-54.

17. Hyde M, Mortimer A, Lowson K. Migraine and antimigraine drugs. In: Rang HP, Dale MM, Ritter JM, Flower RJ, Henderson G, editors. Rang and Dale's Pharmacology. $9^{\text {th }}$ ed. Spain: Churchill Livingstone; 2012. p. 199-202.

18. Tepper SJ, Spears RC. Acute treatment of migraine. Neurol Clin 2009;27(2):417-27.

19. WHO Collaborating Centre for Drug Statistics Methodology. Definition and General Considerations;2016 Available from: http://www.whocc. no/ddd/definition and general considera. [Last cited on 2017 Jun 12].

20. Ghanname I, Ahid S, Berrada G, Belaiche A, Hassar M, Cherrah Y. Trends in the use of antiasthmatic medications in Morocco (19992010). Springerplus 2013;2(1):82.

21. WHO Collaborating Centre for Drug Statistics Methodology. ATC/ DDD Index 2016;2016 Available from: http://www.whocc.no/atc_ddd_ index. [Last cited on 2017 Jun 12]. 